\title{
Serum concentration of adhesion molecules in patients with delayed ischaemic neurological deficit after aneurysmal subarachnoid haemorrhage: the immunoglobulin and selectin superfamilies
}

\author{
J J Nissen, D Mantle, B Gregson, A D Mendelow
}

\begin{abstract}
Objectives-Adhesion molecules are involved in the pathogenesis of cerebral ischaemia and may play a part in the pathophysiology of delayed ischaemic neurological deficit (DIND) after aneurysmal subarachnoid haemorrhage. It was hypothesised that after aneurysmal subarachnoid haemorrhage, adhesion molecules may play a part in the pathophysiology of DIND as reflected by significantly altered serum concentrations in patients with and without DIND.

Methods-In a prospective study, mean serum concentrations of ICAM-1, VCAM-1, PECAM, and E, P, and L-selectin were compared between patients without $(n=23)$ and with $(n=13)$ DIND in patients with World Federation of Neurological Surgeons (WFNS) grades 1 or 2 subarachnoid haemorrhage. Serum was sampled from patients within 2 days of haemorrhage and on alternate days until discharge. Concentrations of adhesion molecules were measured by standard procedures using commercially available enzyme linked immunoabsorbent assays.
\end{abstract}

Results-There were non-significant differences in serum concentrations of ICAM-1 (290.8 $\mathrm{ng} / \mathrm{ml} \quad v \quad 238.4 \quad \mathrm{ng} / \mathrm{ml}$, $\mathrm{p}=0.0525)$, VCAM-1 (553.2 $\mathrm{ng} / \mathrm{ml} v 425.8$ $\mathrm{ng} / \mathrm{ml}, \mathrm{p}=0.053)$, and PECAM $(22.0 \mathrm{ng} / \mathrm{ml}$ $v 21.0 \mathrm{ng} / \mathrm{ml}, \mathrm{p}=0.56)$ between patients without and with DIND respectively. The E-selectin concentration between the two patient groups $(44.0 \mathrm{ng} / \mathrm{ml} v 37.4 \mathrm{ng} / \mathrm{ml}$, $\mathbf{p}=0.33$ ) was similar. The $\mathbf{P}$-selectin concentration, however, was significantly higher in patients with DIND compared with those patients without DIND (149.5 $\mathrm{ng} / \mathrm{ml} v 112.9 \mathrm{ng} / \mathrm{ml}, \mathrm{p}=0.039)$. By contrast, serum L-selectin concentrations were significantly lower in patients with DIND (633.8 $\mathrm{ng} / \mathrm{ml} \quad v \quad 897.9 \mathrm{ng} / \mathrm{ml}$, $\mathbf{p}=\mathbf{0 . 0 1 3 )}$.

Conclusions-Of all the adhesion molecules examined in this study, $P$ and L-selectin are involved in the pathophysiology of DIND after aneurysmal subarachnoid haemorrhage.

(F Neurol Neurosurg Psychiatry 2001;71:329-333)

Keywords: adhesion molecule; delayed ischaemic neurological deficit; subarachnoid haemorrhage; selectin; immunoglobulin
Delayed ischaemic neurological deficit (DIND) remains the leading cause of death and disability after aneurysmal subarachnoid haemorrhage. Although nimodipine prophylaxis reduces the incidence of cerebral infarction from about $33 \%$ to $22 \%$ of patients with subarachnoid haemorrhage, ${ }^{1}$ further strategies are needed to ameliorate the devastating neurological effects of this poorly understood phenomenon.

In the pathogenesis of cerebral ischaemia and reperfusion injury, the importance of leucocyte mediated tissue damage has been shown in both animal and human studies. ${ }^{2} 3$ Recruitment of circulating leucocytes and their interaction with the vascular endothelium involves cellular adhesion molecules (CAMs) a diverse set of macromolecules - the functions of which are pivotal in this process.

In leucocyte-endothelial interactions, the selectin superfamily, the immunoglobulin-like superfamily, and the integrins all play a part.

The selectins ( $\mathrm{P}, \mathrm{E}$, and L-selectin) are transmembrane glycoproteins expressed on activated vascular endothelium (P and E), activated platelets $(\mathrm{P})$, and leucocytes $(\mathrm{L})$, and are involved in rolling and activation of leucocytes. The immunoglobulin-like superfamily (intercellular adhesion molecules, ICAM-1, 2, 3, vascular cell adhesion molecule VCAM-1, platelet-endothelial adhesion molecule, PECAM) are expressed by activated endothelium and act via binding to leucocyte transmembrane proteins-the integrins. This immunoglobulin-integrin interaction is responsible for leucocyte-endothelial firm adherence and subsequent leucocyte migration through the endothelium.

Release of soluble adhesion molecules (sCAMs) into the circulation is known to occur in many diseases. ${ }^{4}$ Although the function of these "shed" molecules is unknown, serum concentrations may correlate with outcomes in various clinical circumstances including severe trauma $^{5}$ and septic shock. ${ }^{6}$

Adhesion molecules have been demonstrated in the pathogenesis of various CNS disorders including bacterial meningitis, ${ }^{7}$ encephalitis, ${ }^{8}$ multiple sclerosis, ${ }^{9}$ and cerebral ischaemia, ${ }^{10}$ but little work has investigated the role of adhesion molecules in delayed ischaemia after subarachnoid haemorrhage. Leucocytes have been found in the structural arteriopathy associated with DIND $^{11-14}$ and in brain infarction, ${ }^{310}$ and therefore adhesion molecules may play a role in the pathophysiology of delayed ischaemia. 
Table 1 Mean serum concentrations of adhesion molecules in patients without and with delayed ischaemic neurological deficit (DIND)

\begin{tabular}{lllllll}
\hline & $\begin{array}{l}\text { ICAM-1 } \\
(\mathrm{ng} / \mathrm{ml})\end{array}$ & $\begin{array}{l}\text { VCAM-1 } \\
(\mathrm{ng} / \mathrm{ml})\end{array}$ & $\begin{array}{l}\text { PECAM } \\
(\mathrm{ng} / \mathrm{ml})\end{array}$ & $\begin{array}{l}\text { E-electin } \\
(\mathrm{ng} / \mathrm{ml})\end{array}$ & $\begin{array}{l}\text { P-selectin } \\
(\mathrm{ng} / \mathrm{ml})\end{array}$ & $\begin{array}{l}\text { L-selectin } \\
(\mathrm{ng} / \mathrm{ml})\end{array}$ \\
\hline No DIND (SE) & $290.8(16.8)$ & $553.2(42.6)$ & $22.0(1.1)$ & $44.0(4.3)$ & $112.9(8.1)$ & $897.9(53.6)$ \\
DIND (SE) & $238.4(19.0)$ & $425.8(42.6)$ & $21.0(1.4)$ & $37.4(4.9)$ & $149.5(17.0)$ & $633.8(93.7)$ \\
p Value & 0.0525 & 0.052 & 0.56 & 0.33 & $0.039^{\star}$ & $0.013^{\star}$ \\
\hline
\end{tabular}

^Statistically significant.

There is evidence from both animal and human studies to support roles for ICAM-1, VCAM-1, PECAM, and E, P, and L-selectins in cerebral endothelial and ischaemic brain injury $^{10}{ }^{15-19}$ and so the aim of this study was to evaluate the concentration of the immunoglobulin and selectin families of adhesion molecules in DIND.

The hypothesis was that after aneurysmal subarachnoid haemorrhage, the selectin and immunoglobulin superfamilies of adhesion molecules may play a part in the pathophysiology of DIND as reflected by significantly altered serum concentrations in patients with DIND versus patients without DIND.

In a prospective study, we have compared serum concentrations of ICAM-1, VCAM-1, PECAM, and E, P, and L-selectin in patients without (group A) and with (group B) delayed ischaemia after aneurysmal subarachnoid haemorrhage.

\section{Patients and methods}

Ethical approval for the study was obtained from the joint ethics committee of the Newcastle and North Tyneside Health Authority. Informed written consent was obtained for all patients included in the study.

PATIENTS

We studied patients referred to the Neurosurgery Unit at Newcastle General Hospital from July 1997 to November 1998 with subarachnoid haemorrhage established by CT or lumbar puncture who were grade 1 or 2 on the World Federation of Neurological Surgeons (WFNS) scale. ${ }^{20}$ All patients were given oral nimodipine prophylaxis for DIND from admission and all had a craniotomy with clipping of intracranial aneurysms.

DELAYED ISCHAEMIC NEUROLOGICAL DEFICIT We defined delayed ischaemic neurological deficit as a new, focal delayed onset neurological deficit not attributable to other causes, with an appropriate rise in middle cerebral arterial transcranial Doppler velocity to greater than $120 \mathrm{~m} / \mathrm{s}$, or MCA/ICA ratio of 3 or greater. Angiography was not routinely used for the diagnosis of DIND. Patients with DIND were treated with hypervoleamia and induced hypertension using inotropes where necessary (DIND refractory to hypervoleamia). Nonsymptomatic rises in Doppler velocities were not considered to be diagnostic of DIND. Clinicians were not aware of sCAM concentrations and analysis of the samples was performed blind to clinical details.

We excluded patients with intercurrent medical conditions or nosocomial infection in which adhesion molecules may play a part. In addition, patients with significant postoperative intracerebral haemorrhage or treatment with endovascular obliteration of ruptured aneurysms were excluded.

SERUM SAMPLES

For each patient, initial serum samples were taken within 48 hours of admission (and always before craniotomy) and subsequent samples on alternate days thereafter until discharge. Specimens were allowed to coagulate and then were centrifuged at $3000 \mathrm{rpm}$ for 12 minutes and the supernatant stored at $-40^{\circ} \mathrm{C}$ before analysis.

We assayed serum concentrations of adhesion molecules using commercially available enzyme linked quantitative sandwich immunoabsorbant assay (ELISA) kits ( $\mathrm{R}$ and $\mathrm{D}$ Systems, Abingdon, UK) in accordance with the supplier's instructions. The assays involved the simultaneous reaction of sCAM (in sample or standard) with monoclonal antibody precoated on the walls of microtitre plate wells, and to an unbound second antibody directed against a different molecular epitope. The second antibody was conjugated to horseradish peroxidase. After removal of unreacted reagents, bound sCAM-HRP antibody was detected by reaction with a horseradish peroxidase specific substrate (tetramethylbenzidine), which yielded a coloured product, proportional to the concentration of sCAM (determined relative to an appropriate standard curve). Absorption measurements were carried out at $450 \mathrm{~nm}$ (and correction wavelength of $650 \mathrm{~nm}$ to eliminate optical imperfections in the plate) using a microtitre plate reader (Dynatech MR5000). We diluted serum samples 20-100 fold (depending on the analyte) before analysis.

\section{STATISTICAL ANALYSIS}

The mean of means were compared between the two groups. Unpaired $t$ tests were used to assess the null hypothesis. A p value $<0.05$ was used to indicate statistical significance.

\section{Results}

We included 36 patients in the study out of a possible total of 46 (10 were excluded, eight for nosocomial infection and two for postoperative intracerebral haemorrhage). Twenty three patients (group A) did not develop DIND and 13 patients did (group B). There were 23 women and 13 men, age range $25-74$ years. The median number of serum samples/patient was five (no DIND) and eight (DIND). This reflects the longer stay in hospital of patients with DIND.

Mean serum concentrations of ICAM-1 and VCAM were lower in patients with DIND than in those without DIND, but this did not reach 
Table 2 Mean serum concentrations of adhesion molecules in patients not requiring and requiring dopamine in delayed ischaemic neurological deficit (DIND)

\begin{tabular}{lllllll}
\hline & $\begin{array}{l}\text { ICAM-1 } \\
(\mathrm{ng} / \mathrm{ml})\end{array}$ & $\begin{array}{l}\mathrm{VCAM}(\mathrm{ng} / \mathrm{ml}) \\
(\mathrm{ng} / \mathrm{ml})\end{array}$ & $\begin{array}{l}\text { EECAM } \\
(\mathrm{ng} / \mathrm{ml})\end{array}$ & $\begin{array}{l}\text { P-selectin } \\
(\mathrm{ng} / \mathrm{ml})\end{array}$ & $\begin{array}{l}\text { L-selectin } \\
(\mathrm{ng} / \mathrm{ml})\end{array}$ \\
\hline $\begin{array}{l}\text { No dopamine } \\
\text { Dopamine }\end{array}$ & 230.6 & 385.5 & 20.59 & 37.8 & 195.3 & 833.9 \\
p Value & 245.1 & 460.3 & 19.9 & 37.0 & 110.9 & 462.3 \\
\hline
\end{tabular}

${ }^{\star}$ Statistically significant.

statistical significance (table 1). The concentration of PECAM demonstrated no significant difference $(22.0 \mathrm{ng} / \mathrm{ml} v 21.0 \mathrm{ng} / \mathrm{ml}, \mathrm{p}=0.56)$ and mean serum concentrations of E-selectin showed no significant difference between group A (44.0(SE 4.3) $\mathrm{ng} / \mathrm{ml}$ ) and group B (37.4(SE 4.9) $\mathrm{ng} / \mathrm{ml})(\mathrm{p}=0.33)$.

There were, however, significant differences in P-selectin and L-selectin concentrations between the two groups. For P-selectin, serum concentrations were significantly higher for patients with DIND than patients without DIND (149.5 (SE 17.0) ng/ml $v 112.9$ (SE 8.14) $\mathrm{ng} / \mathrm{ml}, \mathrm{p}=0.039$ ). For L-selectin, serum concentrations were significantly lower for patients with DIND (897.9 $\mathrm{ng} / \mathrm{ml}$ (SE $53.6 v$ $622.8 \mathrm{ng} / \mathrm{ml}$ (SE 93.7, $\mathrm{p}=0.013$, table 1$)$.

In patients with DIND, there was no significant difference in serum concentrations of L-selectin between samples taken before DIND onset, versus samples after onset of DIND (606.2 (SE 87.8) ng/ml v 667.8 (SE 104.8) $\mathrm{ng} / \mathrm{ml}, \mathrm{p}=0.1$ ). Although there was a trend towards higher P-selectin concentrations after onset of DIND, this did not reach significance (125.5 (SE 13.5) ng/ml v 160 (SE 21.6) $\mathrm{ng} / \mathrm{ml}, \mathrm{p}=0.16)$.

In 12 patients with DIND, seven required dopamine for induced hypertension. There was no statistical difference in ICAM, VCAM, PECAM, and E-selectin between patients requiring dopamine and those not requiring dopamine (table 2). Dopamine use decreased both P-selectin concentration $(195.3 \mathrm{ng} / \mathrm{ml} v$ $110.9 \mathrm{ng} / \mathrm{ml}, \mathrm{p}=0.005)$ and L-selectin concentration (833.9 $\mathrm{ng} / \mathrm{ml} v 462.3 \mathrm{ng} / \mathrm{ml}, \mathrm{p}=0.04)$.

The mean peripheral white cell count showed no significant difference $(10.9 \mathrm{v} 11.0)$ whereas mean platelet count showed a significant difference between groups A and B (262 (SE 14.9) v 349 (SE 30.8), $\mathrm{p}=0.008$ ), (no DIND $v$ DIND respectively).

\section{Discussion}

CEREBRAL ISCHAEMIA, LEUCOCYTES, AND ADHESION MOLECULES

Evidence for a pathological role of leucocytes and adhesion molecules in cerebral ischaemiareperfusion injury exists in both animal and human studies. Animal studies have shown that induced neutropoenia can protect against ischaemia-reperfusion injury. ${ }^{21}$ Okada et al have shown transient expression of ICAM-1 and persistent upregulation of P-selectin in a primate focal ischaemia-reperfusion model. P-Selectin was detected from both postcapillary microvascular endothelium, and from platelets. Non-endothelial, platelet derived P-selectin was significantly correlated with platelet accumulation. ${ }^{22}$ In other rat models, persistent ICAM-1 expression has been shown in a non-reperfusion model, ${ }^{23}$ and Clark et al ${ }^{10}$ demonstrated early ( 6 to 24 hours) endothelial and late (4 to 7 days) parenchymal expression of ICAM-1 in forebrain ischaemia-reperfusion and these correlated temporally and topographically with leucocyte accumulation. Wang et $a l^{24}$ showed increased E-selectin mRNA in ischaemic rat cortex compared with nonischaemic cortex and E-selectin upregulation has been shown in a rat MCA occlusionreperfusion model. ${ }^{25}$ Using immunohistochemical staining, Lindsberg et $a l^{26}$ found upregulation of endothelial ICAM-1 expression in adult human infarcts compared with both non-infarcted hemispheres and control brains.

By using antiadhesion strategies, a role of CAMs in cerebral ischaemia has also been shown using experimental models of both permanent and transient cerebral ischaemia. Antiadhesion therapies to ICAM-1 and integrin subunits have been shown in these models to be protective, with reduction in infarct size. ${ }^{27-29}$

SERUM ADHESION MOLECULES AND CEREBRAL ISCHAEMIA

Circulating sCAMs have been investigated after human stroke. Shyu et $a l^{16}$ found raised ICAM-1 but normal E-selectin within 24 hours of ischaemic stroke in adults. Bitsch et $a l^{17}$ found a peak in expression of ICAM-1 at 24 hours, VCAM at 5 days, and a fall in E-selectin over 5 days. By contrast, ICAM1 and VCAM were not raised in the study by Frijns et al, but E and P-selectin were raised 24 hours after stroke. ${ }^{18}$

\section{ADHESION MOLECULES IN SUBARACHNOID}

HAEMORRHAGE

The role of adhesion molecules in subarachnoid haemorrhage is less clear. Few studies have investigated the changes in adhesion molecules in subarachnoid haemorrhage. In a rat cisterna magna model of subarachnoid haemorrhage, Handa et $a l^{\beta 0}$ showed induction of ICAM-1 expression on the endothelial and medial layers of the basilar artery with a correlation between the degree and timing of basilar spasm and leucocyte inflammatory response within the vessel. Sills $e t a l^{\beta 1}$ demonstrated in a rat femoral artery model of vasospasm that there was early induction of ICAM-1 on the endothelium and showed a direct correlation with an inflammatory response within the vessel wall. Anti-ICAM-1 monoclonal antibodies were given via an intraperitoneal route in the same rat femoral artery model by Oshiro et $a^{32}$ who was able to demonstrate reduced arterial narrowing and less inflammatory infiltrate within the periadventitia. More recently, Polin et $a l^{33}$ have shown significantly increased concentrations of ICAM-1, E-selectin, and VCAM-1 in the CSF in 17 patients with subarachnoid haemorrhage undergoing craniotomy, compared with 16 controls. Concentrations of L-selectin were slightly but not significantly increased. Three patients developed severe or moderate angiographically demonstrated vasospasm and had higher concentrations of E-selectin than other patients with 
subarachnoid haemorrhage. After cisternal subarachnoid haemorrhage in rabbits, Bavbeck et $a l^{34}$ showed that cisternal administration of anti-ICAM-1 antibody or anti-CD18 antibody attenuated vasospasm. When given in combination, the effect was additive.

In this study, we have shown significant differences in serum selectin concentrations between patients who do, and do not develop delayed ischaemic neurological deficits after aneurysmal subarachnoid haemorrhage. Although ICAM-1 and VCAM differences did not reach significance, this may reflect the relatively small patient population. E-Selectin did not show any significant difference between the two groups, but P-selectin concentration was significantly higher and L-selectin concentration significantly lower in those patients with delayed ischaemia.

As this is the first report of serum concentrations of adhesion molecules after subarachnoid haemorrhage, it is difficult to relate our findings to previous CAM studies in subarachnoid haemorrhage. In comparison with studies of sCAM in human stroke, our findings are consistent with raised $\mathrm{P}$-selectin demonstrated by Frijns et $a l^{18}$ and with the reduction in L-selectin in patients with stroke over time as demonstrated by Fassbender et al..$^{15}$ For the other CAMs, comparison is more difficult as for example, ICAM-1 has been shown to both rise, ${ }^{16}$ fall $^{35}$ and remain unchanged ${ }^{18}$ after stroke.

Serum concentrations of shed adhesion molecules may not reflect true local tissue concentrations, ${ }^{4}$ and measurable sCAM will depend on the complex balance between production of de novo CAM or release of preformed CAM, cleavage from the cell membrane, adhesion to counter-receptors, and clearance from the circulation. On the basis of serum concentrations of the selectins and immunoglobulin superfamilies analysed, we conclude that $\mathrm{P}$ and L-selectins may be involved in the pathophysiology of delayed ischaemia. Whether these changes are causal in DID, an epiphenomenon or simply a part of the complex cascade of events in DID requires further study. Similarly, the contribution of platelet derived versus endothelial derived P-selectin is unknown in our patients and further research is needed to ascertain the origin of the P-selectin. Certainly, a platelet origin would be consistent with both the significant rise in peripheral platelet count seen in our patients with DIND and with known evidence suggesting platelet involvement in the pathogenesis of DIND. ${ }^{36} 37$ The reduction in measurable L-selectin may reflect reduced availability in serum due to binding to receptor ligands by activated leucocytes. It is also possible that this results from the hypervolaemia used as part of the treatment for DIND. This is, however, unlikely as no other sCAM concentration fell significantly. Seven of 12 patients with DIND also required dopamine for induced hypertension. Catecholamine inotropes are known to be antiinflammatory and may alter the expression of adhesion molecules. ${ }^{38-40}$ For ICAM, VCAM, PECAM, and E-selectin, no difference was found in sCAM between patients requiring and not requiring dopamine. However, significant reductions in serum concentrations of $\mathrm{P}$ and L-selectin were seen. This may be artefactual due to the small numbers of patients but may be due to an anti-inflammatory effect of dopamine. Unfortunately, patients requiring dopamine were refractory to haemodilution alone and may therefore have more "severe" DIND. In the absence of cerebral blood flow studies, we cannot comment further on this and further research is needed to investigate the effects of inotropes and cerebral expression of CAMs.

Interestingly, there were no statistically significant differences in the sCAM concentrations for P and L-selectins before the development of symptomatic DIND compared with after the onset of symptoms. This may therefore reflect early activation of endothelial cells, leucocyes, or platelets in patients before the onset of clinical symptoms of DIND.

Due to the complex factors determining serum concentrations of adhesion molecules, we cannot exclude a role for ICAM-1, VCAM-1, PECAM, and E-selectin, and further research is required to ascertain this.

The importance of these findings is that they offer a potential therapeutic target for patients with subarachnoid haemorrhage. Because DIND typically occurs between 4 and 14 days after onset of SAH, the opportunity exists for prophylactic anticipatory therapy. Identifying effective methods of prophylaxis obviously depends on knowledge of the pathophysiology of DIND and we present the first human serum evidence of a change in concentration of adhesion molecules in delayed cerebral ischaemia.

In conclusion, on the basis of serum concentrations of adhesion molecules, $\mathrm{P}$ and L-selectin may be involved in the pathophysiology of delayed ischaemic neurological deficit after aneurysmal subarachnoid haemorrhage. Further study is required to elucidate the relevance of serum concentrations of adhesion molecules compared with local cerebral concentrations, to determine the relative contributions of platelets, leucocytes, and endothelium in CAM production, and to determine whether antiadhesion therapy will attenuate delayed ischaemia after aneurysmal subarachnoid haemorrhage.

We acknowledge the contributions of Tom Wooldridge, Alison Blackburn, and Jane Barnes to the study. This research was supported by research grants from the Royal Victoria Infirmary Special Trustees and the Northern Brainwave Appeal.

1 Pickard JD, Murray GD, Illingworth R, et al. Effect of oral nimodipine on cerebral infarction and outcome after subarachnoid haemorrhage. British aneurysm nimodipine trial. BMF 1989;298:636-42.

2 Connolly ES, Winfree CJ, Springer TA, et al. Cerebral protection in homozygous null ICAM-1 mice after middle cerebral artery occlusion: role of neutrophil adhesion in the pathogenesis of stroke. $\mathcal{F}$ Clin Invest 1996;97:209-16.

3 Pozzilli C, Lenzi CL, Argentino C, et al. Imaging of leukocyte infiltration in human cerebral infarcts. Stroke 1985;16:251-5.

4 Gearing AJ, Newman W. Circulating adhesion molecules in disease. Immunol Today 1993;14:506-12.

5 Law MM, Cryer HG, Abraham E. Elevated levels of soluble ICAM-1 correlate with the development of multiple organ failure in severely injured patients. F Trauma 1994;37:100- 
6 Newman W, Beall LD, Carson CW. Soluble E-selectin is found in supernatants of activated endothelial cells and is elevated in serum

7 Granert C, Raud J, Xie X, et al. Inhibition of leukocyte rolling with polysaccharide fucoidin prevents pleocytosis in experimental meningitis in the rabbit. F Clin Invest 1994;93:929-36.

8 Wilcox CE, Ward AM, Evans A, et al. Endothelial cell expression of the intercellular adhesion molecule-1 (ICAM-1) in the central nervous system during acute and chronic relapsing experimental allergic encephalomyelitis. f Neuroimmunol 1990;30:43-51.

9 Canella B, Raine CS. The adhesion molecule and cytokine profile of multiple sclerosis lesions. Ann Neurol 1995;37: 424-35.

10 Clark WM, Lauten JD, Lessov N, et al. Time course of ICAM-1 expression and leukocyte subset infiltration in rat forebrain ischaemia. Molecular and Chemical Neuropathology. 1995;26:213-30.

11 Tanabe Y, Sekata K, Yamada Y. Cerebral vasospasm and ultrastructural changes in cerebral arterial wall. 7 Neurosurg 1978;49:229-38.

12 Handa Y, Kabuto M, Kobayashi H, et al. The correlation between immunological reaction in the arterial wall and the time course of the development of cerebral vasospasm in a primate model. Neurosurgery 1991;28:542-9.

13 Ryba M, Jarzabek-Chorzelska M, Chorzelski T, et al. Is vascular angiopathy following intracranial aneurysm rupture immunologically mediated? Acta Neurochir (Wien) 1992 117:34-7.

14 Crompton MR, The pathogenesis of cerebral infarction following the rupture of cerebral berry aneurysms. Brain 1964;87:491-510

15 Fassbender K, Mössner R, Motsch L, et al. Circulating selectin and immunoglobulin-type adhesion molecules in acute ischaemic stroke. Stroke 1995;26:1361-4.

16 Shyu KG, Chang H, Linn CC. Serum levels of intercellular adhesion molecule- 1 and E-selectin in patients with acute adhesion molecule-1 and E-selectin in pa
ischaemic stroke. $\mathcal{F}$ Neurol 1997;244:90-3.

17 Bitsch A, Klene W, Murtada L, et al. A longitudinal prospective study of soluble adhesion molecules in acute prospective study of soluble adhes
stroke. Stroke 1998;29:2129-35.

18 Frijns CJ, Kappelle LJ, van Gijn J, et al. Soluble adhesion molecules reflect endothelial cell activation after ischaemic stroke and in carotid atherosclerosis. Stroke 1997;28:2214 18.

19 Rosenblum W, Nelson G, Wormley B, et al. Pole of plateletendothelial cell adhesion molecule (PECAM) in platelet adhesion/aggregation over injured but not denuded endothelium in vivo and ex-vivo. Stroke 1996;27:709-11.

20 Drake CG, Hunt WE, Sano K, et al. Report of World Federation of Neurological Surgeons Committee on a universal subarachnoid haemorrhage grading scale. $\mathcal{F} \mathrm{Neu}-$ rosurg 1988;68:985-6.

21 Shiga Y, Onodera H, Matsuo Y, et al. Cyclosporin A protects against ischaemia-reperfusion injury in the brain. Brain Res 1992;595:145-8.

22 Okada Y, Copeland BR, Mori E, et al. P-selectin and intercellular adhesion molecule-1 expression after focal brain cellular adhesion molecule-1 expression after foca

23 Jander S, Kraemer M, Schroeter M, et al. Lymphocytic infiltration and expression of intercellular adhesion molecule- 1 in a photochemically induced ischaemia of the rat cortex. $\mathscr{f}$ Cereb Blood Flow Metab 1995;15:42-51.
24 Wang X, Yue T-L, Barone FC, et al. Demonstration of increased endothelial-leukocyte adhesion molecule- 1 mRNA expression in rat ischaemic cortex. Stroke 1995;26: 1665-9.

25 Zhang RL, Chopp M, Zhang ZG. E-selectin in focal cerebral ischaemia and reperfusion in the rat. $\mathcal{F}$ Cereb Blood Flow Metab 1996;16:1126-36.

26 Lindsberg PJ, Carpen O, Paetau A, et al. Endothelial ICAM-1 expression associated with inflammatory cell response in human ischaemic stroke. Circulation 1996;94: $939-45$

27 Clark WM, Madden KP, Rothlein R. Reduction of central nervous system ischaemic injury by monoclonal antibody to intercellular adhesion molecule. $\mathcal{F}$ Neurosurg 1991;75: 623-7.

28 Chen $\mathrm{H}$, Chopp $\mathrm{M}$, Zhang RL, et al. Anti-CD11b monoclonal antibody reduces ischaemic cell dammage after transient focal cerebral ischaemia in rat. Ann Neurol 1994;35:458-63.

29 Chopp M, Li Y, Jiang N, et al. Antibodies against adhesion molecules reduce apoptosis after transient middle cerebral artery occlusion in rat brain. 7 Cereb Blood Flow Metab 1996;16:578-84.

30 Handa $Y$, Kubota $T$, Kaneko $M$, et al Expression of intercellular adhesion molecule 1 [ICAM-1] on the cerebral artery following subarachnoid haemorrhage in cerebral artery following subarachnoid
rats. Acta Neurochirurgica 1995;132:92-7.

31 Sills A, Clatterbuck RE, Thompson RC, et al. Endothelial cell expression of intercellular adhesion molecule 1 in experimental posthaemorrhagic vasospasm. Neurosurgery. 1997;41:453-60.

32 Oshiro EM, Hoffman PA, Dietsch GN, et al. Inhibition of experimental vasospasm with anti-intercellular adhesion molecule-1 monoclonal antibody in rats. Stroke 1997;28: 2031-8.

33 Polin RS, Bavbek M, Shaffrey ME, et al. Detection of soluble E-selectin, ICAM-1, VCAM-1 and L-selectin in the cerebrospinal fluid of patients after subarachnoid haemorrhage. F Neurosurg. 1998;89:559-67.

34 Bavbeck M, Polin R, Kwan A, et al. Monoclonal antibodies against ICAM-1 and CD18 attenuate cerebral vasospasm after experimental subarachnoid haemorrhage in rabbits. Stroke 1998;29:1930-6.

35 Clark W, Coull B, Briley D, et al. Circulating intercellular adhesion molecule- 1 and neutrophil adhesion in stroke. $\mathcal{F}$ Neuroimmunol 1993;44:123-6.

36 Juvela S. Cerebral infarction and release of platelet thromboxane after subarachnoid haemorrhage. Neurosurgery 1990;27:929-35.

37 Juvela S, Hillbom M, Kaste M. Platelet thromboxane release and delayed cerebral ischaemia in patients with subarachnoid haemorrhage. I Neurosurgery 1991;74:386-92.

38 Uusaro A, Russell JA. Could anti-inflammatory actions of catecholamines explain the possible beneficial effects of supranormal oxygen delivery in critically ill surgical patients? Intensive Care Med 2000;26:299-304.

39 Fortenberry JD, Hubber AR, Owens BS. Inotropes inhibit endothelial cell surface adhesion molecules induced by interleukin-1ß. Crit Care Med 1997;25:303-8.

40 Rainer TH, Lam N, Cocks RA. Adrenaline upregulates monocyte L-selectin in vitro. Resuscitation 1999;43:47-55. 